\title{
Nursing staff's responses to thematic content of patients' expressed worries: observing communication in home care visits
}

\author{
Linda Hafskjold ${ }^{1,2,4^{*}}$ (D), Vibeke Sundling ${ }^{1,2,3}$ and Hilde Eide ${ }^{3}$
}

\begin{abstract}
Background: The aim of the study was to explore the thematic content of older persons' expressed worries in home care visits, and how nursing staff respond to different thematic contents.

Methods: The study had a descriptive, observational design, including 195 audio-recorded Norwegian home care visits with 33 nursing staff and 48 older persons. In all, 638 patient cues/concerns (worries) and subsequent nursing staff's responses were identified using Verona Coding Definitions of Emotional Sequences. A novel thematic coding scheme was used to label the thematic content of the cues/concerns. The nursing staff's responses were grouped based on communicative function as emotion-focused, content-focused or ignoring/blocking the cue/concern. Group difference was analysed using Pearson's chi-squared test, Fisher's exact test, and adjusted residuals.

Results: The theme of worries was associated with elicitation of the cue/concern, either elicited by the nursing staff or spontaneously expressed by the patient (Chi-square, $p<0.001$ ). "Ageing and bodily impairment" was the most common theme (66\%) and was equally elicited by patients and nursing staff. Worries about "Relationships with others" (9\%), "Health care-related issues" (15\%) and "Life narratives and value issues" (9\%) were mainly elicited by nursing staff. The nursing staff response was associated with the theme of worries $\left(p^{<} 0.001\right)$. For the sub-themes of "Ageing and bodily impairment", Coping with existential challenges received more frequently emotion-focused responses (adjusted residuals: 3.2) and Expression of pain felt in the moment were more frequently ignored/blocked (adjusted residuals: 4.0, Fisher's exact test, $p<0.001$ ). For the sub-themes of "Relationships with others", Being a burden more frequently received a content-focused response (adjusted residuals: 2.8), while Losing social ties more frequently received an emotion-focused response (adjusted residuals: 3.1, Fisher's exact test, $p=0.009$ ).

Conclusion: "Ageing and bodily impairment" was the most common theme and more frequently elicited by the older persons than other themes. Emotionally focused nursing staff responses were most common when addressing existential challenges and fear of losing social ties. Whereas nursing staff showed a tendency to ignore patients' spontaneous expressions of pain. Further research should explore the influence of nursing staff's responses on quality of care and patient satisfaction.
\end{abstract}

Keywords: Communication, Emotions, Expressed emotion, Home care services, Older adult, Nursing staff, Observational study, Person-centred communication

\footnotetext{
* Correspondence: Linda.hafskjold@usn.no

${ }^{1}$ Department of optometry, radiography and lighting design, Faculty of

Health and Social Sciences, University of South-Eastern Norway, Drammen,

Norway

${ }^{2}$ National Centre for Optics, Vision and Eye Care, Faculty of Health and Social

Sciences, University of South-Eastern Norway, Kongsberg, Norway

Full list of author information is available at the end of the article
}

(c) The Author(s). 2018 Open Access This article is distributed under the terms of the Creative Commons Attribution 4.0 International License (http://creativecommons.org/licenses/by/4.0/), which permits unrestricted use, distribution, and

reproduction in any medium, provided you give appropriate credit to the original author(s) and the source, provide a link to the Creative Commons license, and indicate if changes were made. The Creative Commons Public Domain Dedication waiver (http://creativecommons.org/publicdomain/zero/1.0/) applies to the data made available in this article, unless otherwise stated. 


\section{Introduction \\ Background}

How care providers communicate with older persons can have a significant impact on older persons' perception of well-being and quality of life, as well as cognitive and functional abilities [1]. Across healthcare settings, the provision of high-quality healthcare depends on the care provider's ability to notice and respond to patients' worries in order to meet patients' care needs, to achieve care outcomes, and to ensure a trusting care relationship [2-7]. Older persons describe high quality care as related to being recognised as a person with a unique history, experiences and competences [8-10], that is an underpinning principle of person-centred care [11].

To achive the goals of high-quality healthcare, nursing staff need to work together with care recipients, and involve them as partners in all steps of the care delivery, that is a hallmark of a person-centred healthcare [12]. Norwegian policy for older people promote active ageing, providing older people to live at home as long as possible [13, 14]. Person-centred healthcare, perserving autonomy and independence, despite illness and functional impariment, with respect to the older person's preferences and values, is an important aspect of the policy. This is in accordance with description of person-centred healthcare tailored towards older people's needs [15] and the World Health Organization strategic objectives to ensure sustainable healthcare systems [16]. To ensure effective care delivery that supports the older person to stay self-reliant and in control over their life, nursing staff need to be aware of how older persons express deterioration of health and well-being [17]. Current research describes the importance of addressing emotional needs of older persons living at home, but few studies have analysed how nursing staff respond to expressed emotional needs during home care visits [18]. Moreover, the research builds mainly on interviews [19-21] and surveys [22-24].

This paper is based on an international research project, the COMHOME study, which focus on how older persons communicate with their care providers [25]. Qualitative studies from COMHOME show that communication in home care mainly is instrumental, focusing on the task at hand [26, 27], similar to reported findings 20 years ago [28]. A study, from Sweden and Denmark found that in home help visits, task completion aims at being "good enough" rather than "brilliant" and that older persons rarely dispute the home help provider's assessment of the task performed [29]. This could be a reason why communication challenges between older persons and nursing staff seem to occur when the conversation takes an unexpected turn away from the instrumental care task, like when the older persons express concerns, have contradicting views, or raise existential issues, as identified in the COMHOME study [26].
Other studies underline the importance of establishing a professional friendship between nursing staff and the older person receiving home care, to elicit the patient perspective, and ensure respect in all steps of care delivery, and to foster a supportive care environment [19]. A well-functioning relationship between the patient and the home care nurse builds on trust, when trust is achieved, the patient's sense of security is increased and loneliness is relieved, especially for persons lacking social support [30]. Moreover, the face-to-face meetings in the home of the patients provide unique information and understanding needed to provide good and safe care [31]. A good patient-nurse encounter in home care was characterised by security, presence, time, respect and seeing the person. Moreover, ensuring that home care nursing staff is able to prioritise time for psychosocial talk, allowing the patient to share emotional struggle, and not only instrumental assistance has been emphasised as an important health-promoting measure for home care services, especially for older persons living with multimorbidity [32].

To identify and quantitatively analyse patient expressions of worries and nursing staff's subsequent responses during emotional talk in observational studies, the "Verona Coding Definitions of Emotional Sequences" (VR-CoDES) has been developed $[33,34]$. The VR-CoDES defines a concern as "a clear and unambiguous expression of an unpleasant current or recent emotion where the emotion is explicitly verbalized" and a cue as the patient's "verbal or non-verbal hint which suggests an underlying unpleasant emotion but lacks clarity" [33]. The COMHOME study has shown that older persons communicate their worries mainly as cues and not as explicitly stated concerns during home care visits $[18,26,35]$. This is also seen in studies in other care settings [36-38], however, these studies do not show what the worries are about. Patients in hospices and primary care are shown to be selective in their communication with nurses, often restricting the worries to physical symptoms [39, 40], but there is no knowledge about the issues raised by the patients in home care.

The COMHOME study has shown that nursing staff more often open up for the patient to elaborate about the worries when nursing staff themselves elicit the expression of worry, or when the patient uses verbal or non-verbal expressions clearly pointing to an unpleasant emotion, making the affective content more clear [41]. Similar response-patterns are also identified in other care settings $[42,43]$. In primary care, robust empirical evidence support that nurses' affective communication is related to both patient and nursing staff satisfaction, and affect is more clearly communicated through speech and vocal tone than through non-verbal channels [7]. To our knowledge no recent studies have investigated the immediate nursing staff 
response to patient expressed worries in home care visits.

Doctors and nurses respond differently to expressions of worries [43, 44]. Nurses more often allow emotions to be disclosed [43]. This may reflect role expectations and healthcare context, as well as how doctors and nurses consider the importance of exploring emotional issues [5, 45-47]. However, patient satisfaction increases when worries are acknowledged and explored [48], and there is a lack of knowledge about how care providers adjust their response according to the thematic content of worries.

There is a need to better understand what happens and how the care provider respond to different themes of worries. Studies indicate that care providers find it difficult to communicate with older persons about existential worries, mental health issues, and issues having an unpleasant emotional value to the person [26, 32, 49]. It is possible that thematic content in emotional expressions perceived as difficult to address by nursing staff, receive less space for discussion and consequently reduce the older persons' opportunity to receive help to resolve and cope with particular worries. This could have an impact on the older persons ability to continue to live a good life at home [32].

Being able to attend to older persons' needs for physical, psychological, social, and spiritual support are described as crucial to help older persons maintain a positive spirit in late life and to cope with potential challenges arising from reduced health or other issues potentially threatening their well-being [50]. Therefore, describing nursing staff's responses related to thematic content of patients' expressed worries may provide an important insight into the verbal disclosure of concerns in home care visits [18].

The aim of this paper is to explore characteristics of the thematic content of older persons' expressed worries in home care visits and nursing staff response to different thematic contents.

\section{Methods}

\section{Design, setting and sample}

The study had a descriptive, observational design $[51,52]$. The data was collected as part of the COMHOME study [25].

\section{Setting and sample}

Between December 2013 and May 2014, audio recordings of 195 home care visits were collected at four Norwegian home care units covering both rural and urban populations. The audio recordings captured communication between older patients ( $\geq 65$ years) and registered nurses (RN) or nurse assistants (NA) during the home care visit.
Nursing staff and patients were recruited based on eligibility criteria and provided informed consent to participate. The nursing staff criteria was being an $\mathrm{RN}$ or a NA having a permanent position and working at the time of data collection. In Norway, RNs and NAs have formal education at bachelor degree and upper secondary school level, respectively. A key management person at each home care unit ensured that all eligible nursing staff received written information about the study. In addition, two members of the research team provided oral information about the study on two occasions at each home care unit. Nursing staff who met the inclusion criteria gave informed consent to participate to the key management person.

The patient criteria was to receive home care during period of data collection and being able to provide informed consent. Effort was made to ensure variation in characteristics of nursing staff (gender, work experience), patients (age and care needs) and visits (e.g. time of day, type of assignments). Nursing staff, well-known to the patients, provided eligible patients with oral and written information. All nursing staff participating in the recruitment process received instructions for recruitment by the research team. Emphasis was put on the importance of checking that the information was correctly understood, encouraging questions, and emphasising that declining to participate or withdraw from the study was unproblematic and of no consequences to the care provided. After a minimum of $24 \mathrm{~h}$, a written informed consent was collected from the patient. To ensure that all patients were confident in their decision to participate, the key management person talked to each patient after the patient had taken part in the study. Three patients declined further participation, none wanted collected data to be deleted.

Table 1 provides an overview of the nursing staff, the older patients, and the characteristics of the home care visits.

One workweek was dedicated for each home care unit to complete data collection. This ensured a minimum of interruption and inconvenience for participating nursing staff, other nursing staff and patients. A digital audio-recorder captured the communication as it naturally unfolded during the entire visit. All nursing staff received instructions on how to operate the digital audio-recorder, excluding the need for the researchers to accompany the nursing staff on their visits. The audio-recorder did not interfere with the nursing staff's ability to assist the patient. Five nurses and five nurse assistants were set as the desired minimum of nursing staff to be recruited based on feasibility and reported numbers to ensure a reliable sample [7, 47].

The visits covered a range of care assignments such as delivering medication, helping with compression stockings 
Table 1 Overview of sample

\begin{tabular}{|c|c|}
\hline \multicolumn{2}{|l|}{ Nursing staff $(n=33)$} \\
\hline Registered Nurses/Nurse Assistants (n) & $16 / 17$ \\
\hline Females/Males (n) & $27 / 6$ \\
\hline Mean age (SD); age range $\mathrm{e}^{\mathrm{a}}$ & $42( \pm 10) ; 23-59$ \\
\hline $\begin{array}{l}\text { Mean years of work experience (SD); } \\
\text { range work experience }{ }^{b}\end{array}$ & $17( \pm 10) ; 1-31$ \\
\hline \multicolumn{2}{|l|}{ Older persons $(n=48)$} \\
\hline Females/Males & $36 / 12$ \\
\hline Mean age (SD); age range & $84( \pm 8) ; 65-94$ \\
\hline Mean $\mathrm{ADL}^{\mathrm{C}}(\mathrm{SD})$; range $\mathrm{ADL}$ & $2,1( \pm 0,7) ; 0-3,7$ \\
\hline $\begin{array}{l}\text { Mean hours of care per week (SD); } \\
\text { range hours of care per week }\end{array}$ & $5( \pm 5): 0,3-21,5$ \\
\hline \multicolumn{2}{|l|}{ Visits $(n=195)$} \\
\hline $\begin{array}{l}\text { Mean length of visits in minutes (SD); } \\
\text { range length of visit }\end{array}$ & $17( \pm 14) ; 1-72$ \\
\hline $\begin{array}{l}\text { Number of visits with Registered } \\
\text { Nurses/Nurse Assistants }\end{array}$ & $98 / 98$ \\
\hline
\end{tabular}

${ }^{\mathrm{a} M i s s i n g}$ data on 2 registered nurses and 2 nurse assistants

${ }^{\mathrm{b}}$ Missing data on 1 nurse assistant

'Activity of Daily Living scores: the level of assistance needed to perform a

range of daily tasks ( $0=$ no assistance needed, $5=$ full assistance needed) [95]

and getting dressed, wound care, attending to personal hygiene, preparing meals, and managing assistive technology. The number of care assignments varied from single tasks to multiple tasks within the same visit. All nursing staff encountered at least three different patients, but could also encounter the same older person in multiple visits. The older person could encounter different nursing staff in multiple visits. Level of familiarity between nursing staff and the individual patient varied, but all nursing staff had access to individual record notes, list of medications and care assignments through the digital patient management system.

\section{Thematic coding of patients' expressions of worry}

The VR-CoDES identified moments when the patient shared his/her worries (cues or concerns) with the nursing staff, allowing the dyad of emotional communication to be analysed. Patients' expression of worries were identified and coded according to VR-CoDES [33], capturing moments where patients raise troubling issues which they want the care providers to address [53].

To code the thematic content of the identifies worries, we developed a coding scheme based on the four over-arching themes derived from an in-depth inductive content analysis of worries expressed in home care: 1) Relationships with others, 2) Health care-related issues, 3) Ageing and bodily impairment, and 4) Life narratives and value issues, and their subcategories [18].

The first theme Relationships with others includes three sub-themes: 1) worries about being a burden, but still needing help from friends, family and nursing staff,
2) worries about losing self-government triggered by how practical assistance was practiced or offered, and 3) worries about losing social ties, risks of losing attachment to significant others.

The second theme Health care-related issues includes two sub-themes, expressions about how: 1) the care exacerbates the problem and 2) the help is being unhelpful; described as inefficient, disappointing, too late, or not helping at all.

The third theme Aging and bodily impairment include one sub-theme; existential challenges, capturing worries about coping with life, pondering over death, or lack of hope for the future. In addition, exclamation of pain, representing bodily sensations or experience caused by aging or some bodily impairment, is included when it appear as the moments of pain limited the older person's ability to manage and cope in the situation. Whereas expressions of pain linked to the care procedure was assigned to the appropriate sub-theme for "Health care-related issues".

The forth theme Life narratives and value issues defines emotional narratives or reflections on value issues.

The coding scheme was developed in a collaborative process between the authors led by the first author (LH). Several drafts of the coding manual were discussed, revised, and then finalized in consensus between the authors. All expressions in the data material could be assigned to one of the four mutually exclusive main themes, and to one of their mutually exclusive sub-themes (Fig. 1).

Figure 1 shows the coding scheme, including examples of actual patient expressions.

\section{Inter-rater reliability of thematic coding scheme}

Cohen's kappa ( $\mathrm{k}$ ) was calculated for a random sample of 78 cues/concerns (16 visits) coded by the first (LH) and second (VS) author independently. For the main themes, simple agreement between the coders was $86 \%$. The inter-rater reliability, taking into account the possibility of the agreement by chance using Cohen's kappa, was $\mathrm{K}=0.68$. For coding of sub-themes, simple agreement was $80 \%$ and inter-rater reliability was $\kappa=0.64$. After establishing inter-rater reliability, the first author (LH) coded the remaining visits. Simple agreement and intra-rater reliability for the first author based 46 cues/ concerns (16 visits) was $93 \%$ and $\kappa=0.91$, respectively.

\section{Care provider responses}

The response was assigned one of 15 eligible, mutually exclusive codes based on the two VR-CoDES dimensions $[34,54]$ : First, whether the response refers to the cue/ concern explicitly or non-explicitly, that is whether or not the nursing staff response maintain wording or key elements of the concern/cue, which reflects the nursing staff's ability to keep focused attention on the patient 


\section{Relationships with others}

- 1.1 Being a burden

- "I think it's horrible to bother them" (Cue a)

- 1.2 Losing self-government

- [The action of the family trying to help tidy for Christmas] "I do get annoyed, they want to chuck it away, they want to throw it away, and this then is hideous [family's opinion of the items thrown away], I do have to laugh at them" (Cue a)

- 1.3 Losing social ties

- "I miss her you know" (Cue a)

\section{Healthcare-related issues}

- 2.1 Exacerbating the problem

- "The worst is when I try to get it [a sock used together with a circulatory machine] on my foot" (Cue a)

- 2.2 Unhelpful help

- "No, you [the home healthcare service] cannot help" (Cue b)

3. Aging and bodily impairment

- 3.1 Coping with existential challenges

- "I try to manage myself, but it's not always easy" (Cue b)

- 3.2 Expression of pain felt in the moment

- Examples of exclamations: "ah", "oi" and "oof” (Cue f), or "ouch, that hurt!" (Cue b)

\section{Life narratives and value issues}

\section{- 4.1 Life narratives}

- "It was a mess, it may have affected me somewhat that too" [the experiences of redecorating the apartment] (Cue b)

- 4.2 Value issues

- "Then no one comes to the aid of people just lying in the hallway here, dying" (Cue b)

Fig. 1 Thematic coding scheme for expressed worries with examples

expression, hinting to the nursing staff's interest for the patient's way of expressing him/herself [55]. Second, the coding system address whether the response provide space or reduce space for further disclosure of the concern/cue, that is whether or not the response invites the patient to talk more about the expressed worries. This indicates if the response communicates an intention of maintaining reciprocity between patient and nursing staff, a change of topical focus, or introduce a complete topic shift [56]. Two VR-CoDES response codes were not coded; "non-explicitly providing space - silence" as it is not applicable to audio-recordings [54] and the code "explicitly reducing space - postponement" which was not identified in the material. The VR-CoDES-response codes were further grouped into three sum-categories based on communicative function: 1) Responses with a focus on the emotion, 2) Responses with a focus on content, and 3) Ignoring/blocking responses [41], Fig. 2. The three sum-categories allowed differentiation of response behaviours that: 1) acknowledge and/or elaborate the expressed emotions and encourage further disclosure of the affective dimension of the expression, 2) pay attention to the factual dimension of the expression, and
3) ignore or divert attention away from the expressed worry. This allows analysis of communicative function with regard to the thematic content of worries.

\section{Statistical analysis}

Statistical analysis was performed with IBM SPSS Statistics, version 24.0 (IBM, Armonk, NY, USA). Missing data were only identified for nursing staff demographic data (Table 1). Frequency and summation statistics were used to describe the sample, themes and nursing staff responses. Differences in response behaviour between the professions (RN or NA) with regard to themes of worries were explored. Pearson's chi-squared test or Fisher's exact test were used to identify group differences relating to cues/concerns, themes of worries, nursing staff responses, and profession. The significance level was set at $<5 \%$, and adjusted residuals (cut-off set at $\leq-2$ or $\geq 2$ ) guided analysis of associations between categorical variables [51]. An adjusted residual exceeding \pm 2 for a given nursing staff response, indicated that the response was more or less likely to occur to a given theme of cues/concern than the other responses. 


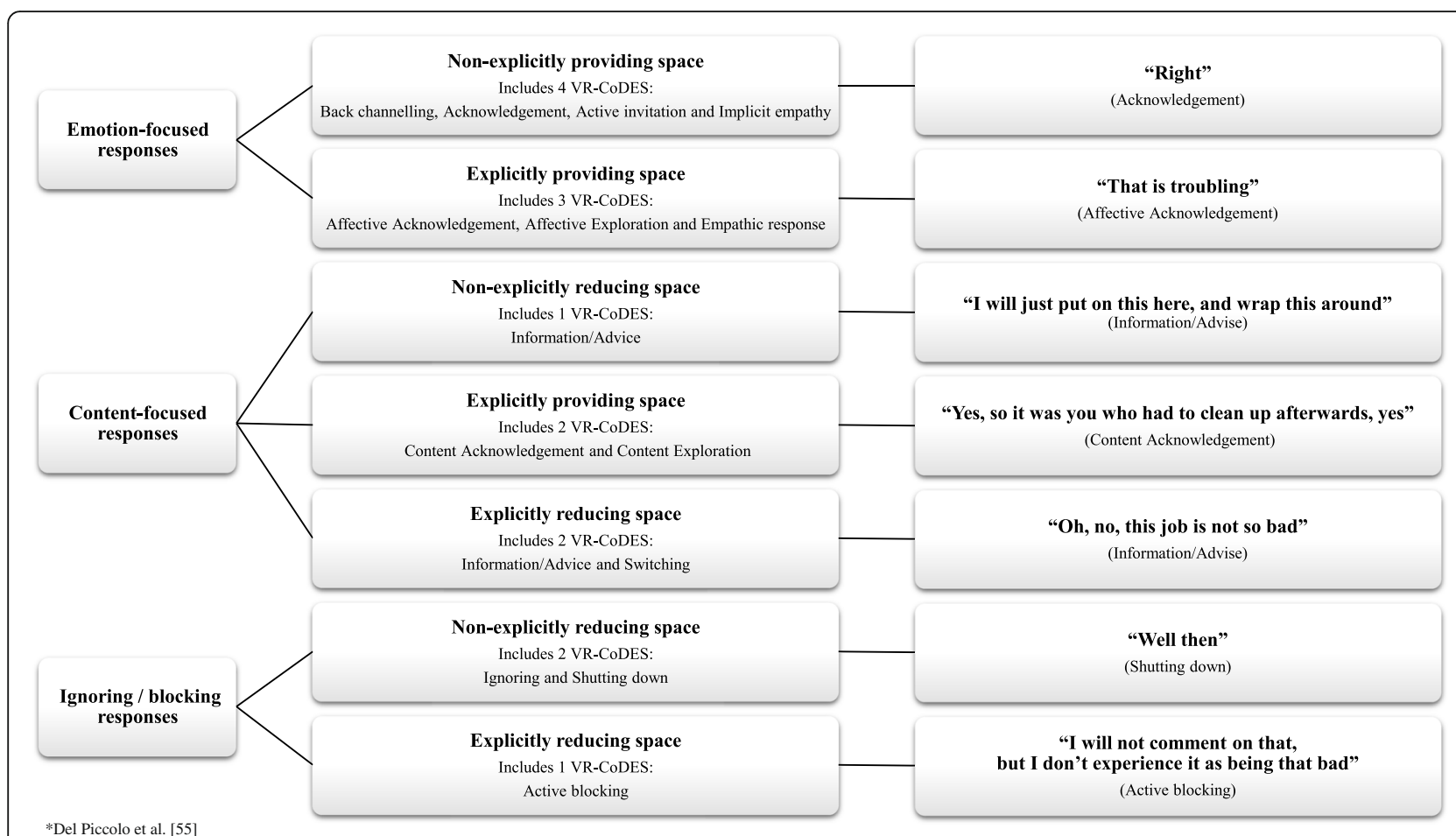

Fig. 2 Adapted Provider response sum-categories

\section{Research ethics}

All steps of the research process and the preparation of this paper were guided by the World Medical Association's Declaration of Helsinki: Ethical principles for medical research involving human subjects [57]. All data handling was in accordance with Norwegian legislation and institutional policy. The Data Protection Official for Research approved the study (project number: 36017). The Research Council of Norway (PraksisVEL, grant no. 226537) and the University College of Southeast Norway, Faculty of Health and Social Sciences, Drammen funded the project. The funding sources played no part in the research.

\section{Results}

The data eligible for analysis in this paper included 638 patient expressed worries (cues/concerns) and 641 subsequent nursing staff responses. Cues/concerns were identified in 74\% (144/195) of the audio-recorded home care visits. A mean of 4 patient cues/concerns ( $\mathrm{SD} \pm 4.2$, range 1 to 25) were identified in visits with expressed worries. Worries were most frequently expressed using metaphors, emphasis, profanities, or expressing uncertainties and hope (VR-CoDES, cue b), followed by the use of vague or unspecified words describing the emotion (VR-CoDES, cue a), and clear and unambiguous expressions describing an unpleasant current or recent emotion (VR-CoDES, concern), Table 2. In addition, a small number of worries were emphasizing unpleasant cognitive or physical states (VR-CoDES, cue c), expressions standing out from the narrative (VR-CoDES, cue d), repetition of neutral words/phrases (VR-CoDES, cue e), and non-verbal hints of unpleasant emotions like crying or sighing (VR-CoDES, cue f).

\section{Content of older persons' worries}

"Ageing and bodily impairment" was the most frequent theme of worries, including 66\% (421/638) of all cues/ concerns. Of these, 69\% (290/421) captured worries about Coping with existential challenges, whereas 31\% (131/421) were Expression of pain felt in the moment. Adjusted residuals show that worries about "Ageing and bodily impairment" were more frequently expressed as hints by use of emphasis, profanities, or expressions of uncertainties and hope (cue b) (Table 2).

Only $15 \%$ (98/638) of the expressed worries were associated with "Health care-related issues". Worries addressing "Relationships with others" $(9 \%$; 59/638) and "Life narratives and value issues" (9\%; 60/638) were least frequently expressed. Only two of the worries related to "Relationships with others" addressed losing self-government. Adjusted residuals showed that worries about "Relationships with others" were more likely expressed using vague or unspecified words for the unpleasant emotion (cue a), and "Life narratives and value issues" were more likely expressed using other type of 
Table 2 Elicitation and type of VR-CoDES - cues and concerns in relation to themes

\begin{tabular}{|c|c|c|c|c|c|c|c|}
\hline \multirow[t]{2}{*}{ Themes } & \multicolumn{2}{|l|}{$\underline{\text { Elicitation of worries }}$} & \multicolumn{4}{|c|}{ VR-CoDES - cues and concerns ${ }^{a}$} & \multirow[t]{2}{*}{ Total } \\
\hline & Nursing staff elicited & Patient elicited & Concern & Cue a & Cue b & Cue c-g & \\
\hline Relationships with others (\%) & $37(63)$ & $22(37)$ & $8(14)$ & $20(34)$ & $30(51)$ & $1(2)$ & $59(100)$ \\
\hline Adjusted Residual & 1,1 & $-1,1$ & 0,9 & $3,6^{* *}$ & $-1,7$ & $-2,5^{* *}$ & \\
\hline Health care-related issues (\%) & $64(65)$ & $34(35)$ & $7(7)$ & $16(16)$ & $67(68)$ & $8(8)$ & $98(100)$ \\
\hline Adjusted Residual & $2,0^{*}$ & $-2,0^{*}$ & $-1,0$ & $-0,2$ & 1,6 & $-1,2$ & \\
\hline Aging and bodily impairment (\%) & $212(50)$ & $209(50)$ & $40(10)$ & $61(14)$ & $277(66)$ & $43(10)$ & $421(100)$ \\
\hline Adjusted Residual & $-4,1^{*}$ & $4,1^{*}$ & $-0,3$ & $-2,5^{* *}$ & $3,4^{* *}$ & $-1,8$ & \\
\hline Life narratives and value issues (\%) & $45(75)$ & $15(25)$ & $8(13)$ & $12(20)$ & $16(27)$ & $24(40)$ & $60(100)$ \\
\hline Adjusted Residual & $3,1^{*}$ & $-3,1^{*}$ & 0,9 & 0,7 & $-5,8^{* *}$ & $7,1^{* *}$ & \\
\hline Total patient expressions of worries (\%) & $358(56)$ & $280(44)$ & $63(10)$ & $109(17)$ & $390(61)$ & $76(12)$ & $638(100)$ \\
\hline
\end{tabular}

Percentages rounded to nearest whole percentage

*Pearson Chi-Square showed significant association between elicitation of worries and themes $\left(p^{<} 0,001\right)$. Adjusted residuals indicate association between themes and who elicit the expression

**Pearson Chi-Square showed significant association between type of patient expressions and themes ( $\left.p^{<} 0,001\right)$. Adjusted residuals indicate association between themes and how worries are expressed

${ }^{a}$ Concern: clear and unambiguous expressions describing an unpleasant current or recent emotion; Cue a: the use of vague or unspecified words describing the emotion; Cue b: hints about hidden concerns; Cue $c-g$ : other type of hints to underlying negative emotion [25]

hints to underlying unpleasant emotion like crying, repetitions or descriptions of unpleasant cognitive or physical states (cue c-g). "Health care-related issues" showed no difference in terms of how the worries were expressed. Table 2 shows who initiated the cues/concerns and how cues/concerns were expressed with regard to theme and VR-CoDES code. Figure 1 provides examples of patient expressions of worries for the themes and sub-themes.

\section{Elicitation of themes}

In general, RNs and NAs most often elicited the expressions of worries. This was especially obvious for expressions related to "Life narratives and value issues" (Table 2). For worries about "Ageing and bodily impairment", the majority of worries related to Coping with existential challenges were elicited by nursing staff, whereas Expression of pain felt in the moment was largely elicited by the patient $(61 \%(177 / 291)$ versus $73 \%$ (95/130), Chi-square $p<0.001)$.

\section{Nursing staff responses}

Overall, $47 \%$ of the responses focused on the emotional component of cues/concerns, followed by responses focusing on content (32\%) and responses ignoring or blocking emotional expressions (21\%), Table 3. Table 4 provides examples of dyads found in the material, illustrating different type of nursing staff responses used in relation to the main themes. How nursing staff responded was associated with theme of worries (Pearson Chi-Square, $p=<0,001)$. There was no significant difference in responses between NAs and RNs.

\section{Responding to different sub-themes within "Ageing and bodily impairment"}

Nursing staff responded differently to "Coping with existential challenges" and "Expression of pain felt in the moment". "Coping with existential challenges" received more frequently responses focussing on the expressed emotion than responses ignoring/blocking the expression of worry (Adjusted residuals 3.2 versus - 4.0, Fisher's Exact Test, $p<0,001)$. Responses to "Expressions of pain felt in the moment" were more frequently ignored/ blocked than responded to with focus on the expressed emotion (Adjusted residuals 4.0 versus - 3.2, Fisher's Exact Test, $p<0,001)$, Table 3.

\section{Responding to different sub-themes within "Relationships with others"}

Worries about "Being a burden" was relatively more often responded to with a content-focused response than with an emotion-focused response (Adjusted residuals 2.8 versus - 3.1, Fisher's Exact Test, $p=0,009$ ), whereas worries about "Loosing social ties" were relatively more often responded to with an emotion-focused response than with a content-focused response (Adjusted residuals 3.1 versus - 3.0, Fisher's Exact Test, $p=0,009)$, Table 3.

\section{Responding to "Healthcare related issues" and "Life Narratives and value issues"}

There were no significant differences between types of responses for sub-themes within "Healthcare related issues" and "Life narratives and value issues", Table 3. Of the responses addressing "Healthcare related issues", $44 \%$ were responding to the emotion, $40 \%$ were responding to the content, and $16 \%$ were ignoring/blocking 
Table 3 Themes and sub-themes by response sum-categories

\begin{tabular}{|c|c|c|c|c|}
\hline Themes & Sub-themes & $\begin{array}{l}\text { Emotion-focused responses } \\
\text { (Adjusted Residual) }\end{array}$ & $\begin{array}{l}\text { Content-focused responses } \\
\text { (Adjusted Residual) }\end{array}$ & $\begin{array}{l}\text { Ignoring/blocking responses } \\
\text { (Adjusted Residual) }\end{array}$ \\
\hline \multirow[t]{4}{*}{ Relationships with others } & Being a burden & $11(-3,1)^{*}$ & $23(2,8)^{*}$ & $5(0,3)$ \\
\hline & Losing self-government & $1(0,2)$ & $1(0,1)$ & $0(-0,5)$ \\
\hline & Losing social ties & $13(3,1)^{*}$ & $3(-3,0)^{*}$ & $2(-0,1)$ \\
\hline & Sum, $n(\%)^{*}$ & $25(42)$ & $27(46)$ & $7(12)$ \\
\hline \multirow[t]{3}{*}{ Health care-related issues } & Exacerbating the problem & $22(0,0)$ & $20(0,0)$ & $8(-0,1)$ \\
\hline & Unhelpful help & $21(0,0)$ & $19(0,0)$ & $8(0,1)$ \\
\hline & Sum, n (\%) & $43(44)$ & $39(40)$ & $16(16)$ \\
\hline \multirow[t]{3}{*}{$\begin{array}{l}\text { Aging and bodily } \\
\text { impairment }\end{array}$} & $\begin{array}{l}\text { Coping with existential } \\
\text { challenges }^{\mathrm{a}}\end{array}$ & $149(3,2)^{*}$ & $89(0,3)$ & $55(-4,0)^{*}$ \\
\hline & $\begin{array}{l}\text { Expression of pain felt in } \\
\text { the moment }\end{array}$ & $45(-3,2)^{*}$ & $38(0-, 3)$ & $48(4,0)^{*}$ \\
\hline & Sum, $n(\%)^{*}$ & $194(46)$ & $127(30)$ & $103(24)$ \\
\hline \multirow{3}{*}{$\begin{array}{l}\text { Life narratives and } \\
\text { value issues }\end{array}$} & Life narratives & $37(1,0)$ & $10(-0,2)$ & $4(-1,3)$ \\
\hline & Value issues & $5(-1,0)$ & $2(0,2)$ & $2(1,3)$ \\
\hline & Sum, n (\%) & $42(70)$ & $12(20)$ & $6(10)$ \\
\hline Total responses ${ }^{a}$ & $n=641(100 \%)$ & $n=304(47 \%)$ & $n=205(32 \%)$ & $n=132(21 \%)$ \\
\hline
\end{tabular}

Percentages rounded to nearest whole percentage. Sum scores in italic indicate the number (\%) of response categories for each main theme

*Fisher's Exact Test showed a significant association between response sum-categories and sub-themes within "Relationships with others" ( $p=0,009)$ and "Aging and bodily impairment" $(p<0,001)$, respectively. Adjusted residuals indicate the association between sub-themes and response behaviour

${ }^{a}$ Three expressions within Existential challenges were met by a double response leaving total number of responses as lager than total number of patient expressions of worries (Table 2)

emotional expressions. Responses to "Life narratives and value issues" were 70\% emotion-focused, $20 \%$ contentfocused and $10 \%$ ignored or blocked the expressed worries.

\section{Discussion and conclusion Discussion}

To the best of our knowledge, this is the first study to explore the thematic content of patient expressed worries in home care visits, and how the nursing staff respond to different thematic content. The findings show that the thematic content to a large extent focus on "Ageing and bodily impairment", that is the older persons' personal struggle to cope with an aging body, reduced physical health and pain, and to accept that life is near the end [18]. Nursing staff response differ according with thematic content of the older persons' worries, especially for older persons' worries about "Relationships with others" and "Aging and bodily impairment".

"Ageing and bodily impairment" represent existential challenges because the addressed circumstance or event challenges the individual person's identity, experience of autonomy, self-worth and/or dignity [58]. Reduced function and chronic pain may leave the person unable to engage in valued activities and force the person in to a state of enduring pain, which hampers the prospect of living a good life. This is shown as a strong trigger for existential challenges which can lead to death anxiety
[59], reflecting the importance of supportive nursing staff responses to such worries $[60,61]$.

Moreover, bodily impairment may influence the older person's ability to communicate properly, and act as a barrier for communication, and nursing staff may experience the older person's bodily impairment as an obstruction to communication, and a barrier to respond effectively to expressions of existential loneliness among older persons [62]. The nursing staff's lack of confidence in own ability to correctly interpret the older persons' care needs in these situations hamper their ability to provide effective care [62]. An international task force of experts have emphasised the importance of implementation strategies to prevent functional decline in older persons living in nursing homes to ensure quality and efficient care for older persons living in the community [63]. Loss of mobility and social support, cognitive decline, iatrogenic events, and progression of disease are described by the task force as driving factors of functional decline among older persons. These are all issues expressed as causing worry by the older persons in this study. This highlights the importance of ensuring that these issues are taken into consideration when the nursing staff evaluate home care needs of older persons. Moreover, a clinical practice that includes the older person's perspective and worries about functional decline and bodily impairment is likely efficient in ensuring the older person's ability to continue to live a good life in 
Table 4 Dyads illustrating different combinations of main themes and type of responses ${ }^{a}$

\begin{tabular}{|c|c|c|c|}
\hline Themes & Patient expression & $\begin{array}{l}\text { Examples of responses assigned to the three } \\
\text { sum-categories of responses }\end{array}$ & \\
\hline \multirow[t]{3}{*}{$\begin{array}{l}\text { Relationships } \\
\text { with others }\end{array}$} & $\begin{array}{l}\text { "If it gets much, a lot, then the nerves kicks in } \\
\text { you see" [Talking about a family member] }\end{array}$ & $\begin{array}{l}\text { "Yes that's..." [Pauses to allow the } \\
\text { patient to continue] }\end{array}$ & $\begin{array}{l}\text { Emotion-focused } \\
\text { responses }\end{array}$ \\
\hline & $\begin{array}{l}\text { "Poor thing, yes, she is very clever, but I do feel sorry } \\
\text { for them, having to work on this" [Worries that the } \\
\text { nursing staff thinks caring for her wound is not a } \\
\text { nice task, focus is on the relation not the care delivery] }\end{array}$ & $\begin{array}{l}\text { "It is our job you know" [Provides } \\
\text { information/advice] }\end{array}$ & $\begin{array}{l}\text { Content-focused } \\
\text { responses }\end{array}$ \\
\hline & $\begin{array}{l}\text { "Oh, well, a lot of stuff, you have to deal with a lot } \\
\text { of strange stuff because of me" [Patient is getting } \\
\text { dressed, focus is on the relation not the care delivery] }\end{array}$ & $\begin{array}{l}\text { [Nursing staff do not comment, } \\
\text { focus on next task] }\end{array}$ & $\begin{array}{l}\text { lgnoring / blocking } \\
\text { responses }\end{array}$ \\
\hline \multirow[t]{3}{*}{$\begin{array}{l}\text { Health care- } \\
\text { related issues }\end{array}$} & $\begin{array}{l}\text { "You see, there is no point telling the doctor about this, } \\
\text { I don't get any answers anyway" [Discussing need for } \\
\text { medical care] }\end{array}$ & $\begin{array}{l}\text { "No?" [Tone of voice invite the } \\
\text { patient to elaborate] }\end{array}$ & $\begin{array}{l}\text { Emotion-focused } \\
\text { responses }\end{array}$ \\
\hline & $\begin{array}{l}\text { "Everything is just yuck" [The nursing staff has first } \\
\text { suggested that the patient needs to eat more] }\end{array}$ & $\begin{array}{l}\text { "No, but it is just so that if you do, you } \\
\text { don't have to get so tired because like it } \\
\text { is, you don't get much nutrition, and then } \\
\text { you have no energy" [Provides information/advice] }\end{array}$ & $\begin{array}{l}\text { Content-focused } \\
\text { responses }\end{array}$ \\
\hline & $\begin{array}{l}\text { "I do feel the male staff is the worst" [ls not happy } \\
\text { with some of the staff at a care service institution] }\end{array}$ & $\begin{array}{l}\text { "Yes, no, I won't comment on that. But I don't } \\
\text { see it like that." [Shuts down further discussion, } \\
\text { the topic changes] }\end{array}$ & $\begin{array}{l}\text { lgnoring / blocking } \\
\text { responses }\end{array}$ \\
\hline \multirow[t]{3}{*}{$\begin{array}{l}\text { Aging and bodily } \\
\text { impairment }\end{array}$} & $\begin{array}{l}\text { "I try to manage myself, but it's not always easy" } \\
\text { [The patient shares her thoughts on being dependant } \\
\text { of home care because of bodily impairment] }\end{array}$ & $\begin{array}{l}\text { "No" [Tone of voice invite the patient to } \\
\text { elaborate] }\end{array}$ & $\begin{array}{l}\text { Emotion-focused } \\
\text { responses }\end{array}$ \\
\hline & $\begin{array}{l}\text { "It's this damn knee!" [The patient spontaneously } \\
\text { raises this topic] }\end{array}$ & $\begin{array}{l}\text { "Do you have pain in your knee?" [The nursing } \\
\text { staff asks specifically about the content and } \\
\text { maintains wording used by patient] }\end{array}$ & $\begin{array}{l}\text { Content-focused } \\
\text { responses }\end{array}$ \\
\hline & $\begin{array}{l}\text { "And I understand, I am not feeling very fit these days } \\
\text { you see" [The patient talks about trying to cope with } \\
\text { reduced function] }\end{array}$ & $\begin{array}{l}\text { "No, but you're fine. You just need to take your } \\
\text { time moving about." [Shuts down further } \\
\text { discussion, the topic changes] }\end{array}$ & $\begin{array}{l}\text { lgnoring / blocking } \\
\text { responses }\end{array}$ \\
\hline \multirow[t]{3}{*}{$\begin{array}{l}\text { Life narratives } \\
\text { and value issues }\end{array}$} & $\begin{array}{l}\text { "No, that was..." [Shares a story about experiencing } \\
\text { a loss in the family] }\end{array}$ & $\begin{array}{l}\text { " } m m \text { ?" [Tone of voice invite the patient } \\
\text { to elaborate] }\end{array}$ & $\begin{array}{l}\text { Emotion-focused } \\
\text { responses }\end{array}$ \\
\hline & $\begin{array}{l}\text { "Very sad that it always has to hit the best of us" } \\
\text { [Shares a story about experiencing a loss in the family] }\end{array}$ & $\begin{array}{l}\text { "Yes, many people experiences this" [Provides } \\
\text { general information] }\end{array}$ & $\begin{array}{l}\text { Content-focused } \\
\text { responses }\end{array}$ \\
\hline & $\begin{array}{l}\text { "Yes, it is, but when we ..." [Starts telling about } \\
\text { traditions from younger days, but gets interrupted] }\end{array}$ & $\begin{array}{l}\text { "Yes, now a days it is a lot of pressure" [Shuts } \\
\text { down further discussion, the topic changes] }\end{array}$ & $\begin{array}{l}\text { lgnoring / blocking } \\
\text { responses }\end{array}$ \\
\hline
\end{tabular}

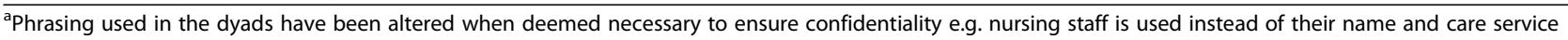
is used instead of the name of the institution

their own home and has potential to reduce or postpone the need for transferal to a nursing home. There is some evidence indicating that investments in home care services may influence the need for nursing homes, although the evidence is weak and has methodological challenges [64].

In this study, the older person's effort to cope with functional decline also raises existential issues for the person and is captured by the main theme "Ageing and bodily impairment". Because of the high frequency of worries about existential issues in home care, there is a need for communication training of nursing staff to ensure sensitivity to these worries, and to provide nursing staff with adequate strategies to provide support. What type of responses older persons prefer and perceive as supportive in different situations are yet to be explored. However, increased communication skills may have the potential to enhance the experienced quality of care $[7,8]$, prevent unnecessary suffering [65] and increase the nursing staff's perception of being competent when facing challenging communication in home care [26, 27, 62].

In general, the older persons in our study spontaneously expressed a greater number of worries compared to patients in other care situations in previous studies $[35,36,38]$. This was especially prominent for the theme "Ageing and bodily impairment", which had equal distribution of nursing staff- and patient-elicited cues/concerns.

The fact that nursing staff were more prone to elicit cues/concerns for other themes of worries than "Ageing and bodily impairment" may be linked to features relating to the older person, the nursing staff, or the theme itself. One interpretation could be that older persons are 
more inclined to share worries about "Ageing and bodily impairment". Another interpretation could be that nursing staff focus less on issues relating to ageing and bodily impairment, leading older persons to initiate such worries by including the topics into the conversation. Finally, this could be related to nursing staff finding it difficult to be supportive and helpful when facing such worries, because they tap into existential issues and need for spiritual support, an area where nursing staff lack competence $[26,66,67]$. Consequently, nursing staff may feel uneasy and wait for the older person to include these topics into the conversation rather than introducing them.

When exploring responses used by nursing staff in relation to worries about "Ageing and bodily impairment", our findings revealed that existential challenges were responded to with an emotional focus and thereby inviting the older person to talk more about the topic, whereas expressions about pain were more likely to be ignored. Hence, the nursing staff in our study seem to be attentive when the expressions include a reference to existential challenges, but avoiding potentially challenging situations [26] by ignoring the patient's expressions of pain. This may indicate that nursing staff do recognise the older person's need to share his/her worries about existential issues and respond in a way that allows the older person to talk more about the topic. This supports other research that emphasises that nursing staff need strategies for dealing with existential issues in a more profound way than simply allowing the person to express him/herself $[62,66]$.

When the nursing staff ignore the spontaneous expressions of pain, this may not be a conscious response strategy, but rather an indication of the nursing staff becoming less responsive or even disinterested over time, with regard to patients known to be expressive about their pain [50,68]. In this way, they may not reflect on whether this could be the older person's way of hinting to how the pain is emotionally challenging or overwhelming, but rather interpret this as "normal" for the situation at hand. Addressing psychosocial aspects of living with chronic pain have been emphasised as salient and often neglected by care providers [69].

Inadequate pain management may lead to adverse physical and psychological patient outcomes, like reduced wound healing, reduced immune system response, negative effects on vital bodily functions and reduced patient mobility [70]. Nursing staff sensitivity towards the patient's experience of pain and efficient pain management may consequently prevent or reduce functional decline from poor pain management. This has been emphasised as essential for practicing efficient geriatric medicine and care in the setting of nursing homes [63], and is likely equally important in home care for older persons.
Given the assumption that a person's experience of pain can challenge a person's emotional well-being, the nursing staff's evaluation of and attention to expressed worries during home care delivery will likely influence their ability to tailor the care in accordance to person-centred principles, like practicing holistic care and eliciting the patient perspective [11]. Ensuring high quality pain management as part of home care services includes tailored care for the emotional aspects of living and coping with pain, and the influence of daily life of the older person. Evidence support that home care nursing staff and their patients develop a relationship that allow home care nursing staff detailed insight into the personal life of the patient, and therefore a more comprehensive picture of the person's life story than in a hospital setting [30]. This highlights a need for collaboration between nursing staff, who provide the daily care and observe how pain and bodily impairment impact the older person's life, and the general practitioners and other healthcare services, to provide a holistic approach at all levels of care delivery. This is promoted as essential to provide person-centred care for older persons [15].

Both existential challenges and pain management capture worries that involve older persons' perceived self-determination, functional status, and effort to maintain health [18]. These elements are highlighted as essential to ensure the ability of older persons to continue a good life living at home, and are important care outcomes for home care services [71-75]. Our study supports recommendations made by other studies [26, 76], that existential challenges and pain management should be emphasized in communication skills training for students and nursing staff working in home health care. Moreover, our study indicates that addressing how to cope with chronic pain and reduced functional ability caused by pain, may be important to include in communication training of nursing staff together with existential issues like the influence of an aging body on a person's identity. How to remain sensitive and responsive may be particularly important in relation to these issues, including the nursing staff's ability to listen [68] and to respond in a supportive way [41], which both are essential components in person-centred quality care $[6,12]$.

"Relationships with others", and "Life narratives and value issues", which address psychosocial aspects [18], were the least frequently expressed worries in our study. The findings were somewhat surprising to the authors. Both themes are assumed to be relevant for the experience of isolation and loneliness [18], thereby potentially influencing health and well-being of older persons [77, 78], and seen as important challenges to manage in care of older persons [17]. Therefore, we expected these themes to be frequently observed. One reason for our findings could 
be that the care setting is characterised by task focused communication [27] that places the care tasks and related issues in focus. Therefore, the patients may by nature experience the company of the nursing staff as supportive and thereby drawn the attention away from potentially worrying relational issues or important life events.

This study also found that older persons' worries about "Relationships with others" were responded to differently depending on the sub-theme. The sub-theme "Being a burden" received a higher proportion of content-focused responses, while the sub-theme "Losing social ties" received more emotion-focused responses. This may indicate that nursing staff perceives responding to the emotion as the best approach to worries about losing significant others, allowing the older persons to explore their feelings using their own words and following their own train of thoughts. The experience of being a burden may be seen as best addressed by directing the older person's attention the factual aspects of the situation. Both type of responses indicate that the act of whole-heartedly listening to the patient is essential because it facilitates the person's perspective and fosters the care relationship [68].

Responding to content when addressing issues relating to being a burden to others, may represent how nursing staff perceive best practice as providing information, reasoning or solutions, by presenting facts or understandings, helping the older person to gain perspective on the situation or circumstance triggering the unpleasant emotion. This has been argued as a more effective approach in clinical communication when trying to help patients to regulate worry as compared to focusing on the affective component of the patient's expression [79]. However, the type of responses focusing on thematic content is perceived as only moderately supportive and most effective when combined with statements that also acknowledge the affective component of the person's worry [65]. Given the unresolved issues relating to when and if an affective focus is preferred by patients and when emotion-focused responses may contribute to more effective care delivery, further research need to explore cause and effect on outcomes relating to patient preferences, patient health, and the care relationship.

For "Life narratives and value issues", expressions of worries facilitated by nursing staff was particularly prominent. This theme was also dominated by responses that allowed the patient to talk more about their worries. Evidence supports the importance of nursing staff engaging in older persons storytelling to allow shared understanding about their life-story, and to foster rapport and deepen the care relationship [80]. This emphasises that nursing staff working in home care should continue to be sensitive to the older person's need to share narratives and important experiences from their own life.
Only two expressions were related to worries about "Losing self-government". Moreover, a relatively small proportion of expressions concerned "Health-care-related issues". Therefore, it appears that older persons rarely express worries regarding help being experienced as invading or insensitive to their preferences. Other studies have described the importance of detecting and disclosing such feelings in order to provide efficient care and to succeed in helping older persons to live a good life in their own homes $[81,82]$. One reason for this finding may be that older persons may have difficulty in expressing dissatisfaction with the care provided and how the help is organized by the nursing staff. In turn, such reluctance may hamper the nursing staff's ability to provide person-centred care, because the individual preferences, experiences, and ideas about what care needs are not shared by the patient [83]. Another explanation could be that nursing staff is already responsive and sensitive, and therefore care provision is rarely an issue causing worry. Based on these findings, it is important to examine further how older persons are included in care management and decisions on a daily basis, how to best involve them, and nursing staff strategies for doing so.

Emotion-focused responses, allowing the older person to elaborate on worries may serve to build the relationship through sharing of experiences. The nursing staff show respect for the older person by actively listening and allowing a shared understanding of events that may influence how the older person understands and sees him/herself at the present time. From this perspective, emotion-focused responses may be a way of practising person-centred communication [82, 84]. However, this depends on whether or not the nursing staff actively use the information to tailor the care in accordance with the perspectives raised by the older person. Limiting the engagement with the older person's worries to allowing him/her to talk about these issues, deny the important function of offering new perspectives that can help the older person to cope better with the situation and regulate the experience of worries [85]. A person's subjective experience of important circumstances or conditions in life, such as relational issues or threats to personal health and well-being, may all cause worries and distressful thoughts leading to the need to share, discuss, and seek comfort and advice in others [85]. Evidence suggests that older persons' perceived well-being and life satisfaction are positively correlated with perceived good health, absence of worry and self-esteem [86]. This suggests that supportive responses-providing explicitly relevant information to aid understanding, offering a solution to a problem, providing comfort or emotional support, or helping the older person to explore what is experienced as worrying $[65,85]$ may be 
important to facilitate a general and sustained feeling of well-being.

Although there are uncertainties about the effects of engaging with patients' emotional cues [87], responsiveness to emotional expressions is emphasised as important to manage communication challenges and to prevent unnecessary suffering for the patient $[26,35,76]$. Recognising and responding to emotions tap into preferences and values of the individual patient $[82,88]$, and potentially strengthen the care relationship [84, 89].

\section{Strengths and limitations}

The relatively large study sample strengthen the findings of the study, especially because the study sample had features related to care assignment, nursing staff and patients that were similar to those described as typical of home care visits [71, 73, 74]. The assumption that audio-recorded data is a valid source to use in communication ratings is supported by other studies, communication ratings using audio and video highly correlate [90], and audio-recording seems to have little influence on the actual communication unfolding between the care provider and the patient [91]. Nevertheless, given that knowledge about emotional talk between older persons and nursing staff in home care is scarce, there is a chance that vital variables have been unknowingly omitted.

The coding scheme focusing on the thematic content in older persons' expressed worries builds on findings from qualitative in-depth analysis of emotional talk unfolding in care situations extracted from the study sample [18]. This empirically driven development may have contributed to strengthening the validity of the coding scheme and ensuring relevance for the setting being analysed [92]. This is further supported by how all cues/concerns could be assigned to a particular theme and related sub-theme, and the substantial agreement between coders [93]. The transferability of the coding scheme can only be evaluated though conducting studies that apply the coding scheme to samples that are representative of other care settings and populations.

The coding rule given by VR-CoDES to assign all periods of silence the code non-explicitly reducing space by ignoring the cue or concern [54] may be a source of bias. We know that silence is a communication strategy found to elicit concerns [94]. Hence, this way of coding may overestimate the number of responses "non-explicitly ignoring" patients' worries, painting a picture of nursing staff as more inclined to reduce space for further emotional disclosure than actually being the case. However, to code a pause as "silence" requires a period of minimum three seconds of no talk [54]. This was very rare in this study and hence unlikely to influence the results.

\section{Conclusion}

The novel coding scheme, designed to differentiate thematic the content of older persons' worries captured by VR-CoDES, allows subsequent nursing staff's responses to be analysed with regard to thematic content of worries. Worries about "Ageing and bodily impairment" are most frequently expressed, and spontaneously elicited by the older person in home care. Nursing staff address emotions when the expressed worries regard existential challenges, fear of losing social ties, or captured life narratives and value issues important for the older person. Nursing staff focus on the content when responding to the experience of being a burden and are more likely to ignore spontaneously expressed pain. Further research exploring the influence of nursing staff's use of different type of responses on quality of care and patient satisfaction is needed. Research investigating how nursing staff address and tailor care towards existential issues, including coping with changes caused by the aging and living with pain, seems salient to ensure quality care and person-centred home care delivery. Our findings show that characteristics of thematic content of patients' worries and nursing staff's responses are associated, and is likely valuable to include in communication training for students and nursing staff.

\section{Abbreviation}

ADL: Activity of daily living; COMHOME: Person-centred communication with older people receiving healthcare; NA: Nurse Assistant; RN: Registered Nurse; VR-CoDES: Verona coding definitions of emotional sequences

\section{Acknowledgements \\ We are grateful to all participants for allowing the communication to be recorded and included in the study. Many thanks to the participating home care units for making data collection possible. Appreciation is also expressed to our competent research assistant, Helene Rintalan, for her help in coding the material. Finally, we acknowledge our fellow researchers at our institution and our colleagues in the COMHOME project for providing us with valuable input and feedback during the research process.}

\section{Funding}

This study was supported by the Research Council of Norway (PraksisVEL, grant no. 226537) and the University College of Southeast Norway, Faculty of Health and Social Sciences, Drammen. The funding sources were not involved in the research or the preparation of the article. The views expressed are of the authors and do not necessarily reflect those of the funding bodies.

\section{Availability of data and materials}

The analysed datasets are not publicly available due to possible intrusion of privacy linked to demographic information on the participants.

\section{Authors' contributions}

LH, VS and HE made substantial contributions to the conception and design of the study. LH was responsible for acquisition of data in close collaboration with HE and VS. LH and VS prepared the data for analysis. LH, VS and HE participated in analysis and interpretation of data. LH, VS and HE drafted the article and revised it critically for important intellectual content, and gave final approval of the version to be submitted. All authors have worked to ensure the integrity of the research presented in this study. 


\section{Ethics approval and consent to participate}

The Regional committees for Medical and Health Research Ethics in Norway, by the committee REC South East B, reviewed the research proposal (study protocol number 2013/1626/REK sør-øst B). The committee ruled that no formal ethics approval was required in this particular case. The Norwegian Social Science Data Services (NSD) approved the study (project ID 36017). All participants signed an informed consent form. Data holding potential risk of disclosing identifiable information about participants has been unidentified in the presentations.

\section{Consent for publication}

Not applicable.

\section{Competing interests}

The authors declare that they have no competing interests.

\section{Publisher's Note}

Springer Nature remains neutral with regard to jurisdictional claims in published maps and institutional affiliations.

\section{Author details}

${ }^{1}$ Department of optometry, radiography and lighting design, Faculty of Health and Social Sciences, University of South-Eastern Norway, Drammen, Norway. ${ }^{2}$ National Centre for Optics, Vision and Eye Care, Faculty of Health and Social Sciences, University of South-Eastern Norway, Kongsberg, Norway. ${ }^{3}$ Science Centre Health and Technology, Faculty of Health and Social Sciences, University of South-Eastern Norway, Drammen, Norway. ${ }^{4}$ Faculty of Health and Social Sciences, University of South-Eastern Norway, PoBox 7053, N-3007 Drammen, Norway.

Received: 16 January 2018 Accepted: 13 July 2018

Published online: 03 August 2018

\section{References}

1. Williams K, Kemper S, Hummert ML. Enhancing communication with older adults: overcoming elderspeak. J Psychosoc Nurs Ment Health Serv. 2005; 43(5):12-6.

2. Lelorain S, Bredart A, Dolbeault S, Sultan S. A systematic review of the associations between empathy measures and patient outcomes in cancer care. Psychooncology. 2012;21(12):1255-64.

3. Tay LH, Hegney D, Ang E. Factors affecting effective communication between registered nurses and adult cancer patients in an inpatient setting: a systematic review. Int J Evid Based Healthc. 2011;9(2):151-64.

4. Zimmermann C, Del Piccolo L, Finset A. Cues and concerns by patients in medical consultations: a literature review. Psychol Bull. 2007;133(3):438-63.

5. Riley R, Weiss MC, Platt J, Taylor G, Horrocks S, Taylor A. A comparison of GP, pharmacist and nurse prescriber responses to patients' emotional cues and concerns in primary care consultations. Patient Educ Couns. 2013;91(1): 65-71.

6. Pincus T, Holt N, Vogel S, Underwood M, Savage R, Walsh DA, Taylor SJ. Cognitive and affective reassurance and patient outcomes in primary care: a systematic review. Pain. 2013;154(11):2407-16.

7. Haskard KB, DiMatteo MR, Heritage J. Affective and instrumental communication in primary care interactions: predicting the satisfaction of nursing staff and patients. Health Commun. 2009;24(1):21-32.

8. Buch ED. Senses of care: embodying inequality and sustaining personhood in the home care of older adults in Chicago. Am Ethnol. 2013;40(4):637-50.

9. Capezuti $E$, Hamers JP. Perspectives on how to improve the nursing care of older adults. Int J Nurs Stud. 2013;50(9):1153-5.

10. Cooney A, Dowling M, Gannon ME, Dempsey L, Murphy K. Exploration of the meaning of connectedness for older people in long-term care in context of their quality of life: a review and commentary. Int J Older People Nursing. 2014;9(3):192-9.

11. McCormack B, McCance T. Person-centred practice in nursing and health care: theory and practice. 2nd ed. Chichester: Wiley-Blackwell; 2017.

12. Coulourides Kogan A, Wilber K, Mosqueda L. Moving toward implementation of person-centered Care for Older Adults in communitybased medical and social service settings: "you only get things done when working in concert with clients". J Am Geriatr Soc. 2016;64(1):e8-14.
13. HOD. Fremtidens primærhelsetjeneste - nærhet og helhet [The primary health and care services of tomorrow - localised and integrated]. Oslo, Norway: Helse- og omsorgsdepartementet; 2015.

14. HOD. Morgendagens omsorg [Future Care]. Oslo, Norway: Helse- og omsorgsdepartementet; 2013.

15. Kogan AC, Wilber K, Mosqueda L. Person-centered Care for Older Adults with chronic conditions and functional impairment: a systematic literature review. J Am Geriatr Soc. 2016;64(1):e1-7.

16. Zsuzsanna J, Agis DT. Health 2020 - achieving health and development in Today's Europe. Open Access Macedonian J Med Sci. 2014;2(3):499-505.

17. Dale B, Soderhamn U, Soderhamn O. Self-care ability among home-dwelling older people in rural areas in southern Norway. Scand J Caring Sci. 2012; 26(1):113-22.

18. Hafskjold L, Eide T, Holmstrom IK, Sundling V, van Dulmen S, Eide H. Older persons' worries expressed during home care visits: exploring the content of cues and concerns identified by the Verona coding definitions of emotional sequences. Patient Educ Couns. 2016:99(12):1955-63.

19. Lindahl B, Liden $\mathrm{E}$, Lindblad BM. A meta-synthesis describing the relationships between patients, informal caregivers and health professionals in home-care settings. J Clin Nurs. 2011;20(3-4):454-63.

20. Fleischer S, Berg A, Zimmermann M, Wüste K, Behrens J. Nurse-patient interaction and communication: a systematic literature review. J Public Health. 2009;17(5):339-53.

21. Caris-Verhallen WM, Kerkstra A, Bensing JM. The role of communication in nursing care for elderly people: a review of the literature. J Adv Nurs. 1997; 25(5):915-33.

22. Borg C, Hallberg IR, Blomqvist K. Life satisfaction among older people (65+) with reduced self-care capacity: the relationship to social, health and financial aspects. J Clin Nurs. 2006;15(5):607-18.

23. Karlsson S, Edberg AK, Jakobsson U, Hallberg IR. Care satisfaction among older people receiving public care and service at home or in special accommodation. J Clin Nurs. 2013;22(3-4):318-30.

24. Steptoe A, Deaton A, Stone AA. Subjective wellbeing, health, and ageing. Lancet. 2015;385(9968):640-8.

25. Hafskjold L, Sundler AJ, Holmstrom IK, Sundling V, van Dulmen S, Eide $H$. A cross-sectional study on person-centred communication in the care of older people: the COMHOME study protocol. BMJ Open. 2015; 5(4):e007864.

26. Sundler AJ, Eide H, van Dulmen S, Holmstrom IK. Communicative challenges in the home care of older persons - a qualitative exploration. J Adv Nurs. 2016;72(10):2435-44.

27. Kristensen DV, Sundler AJ, Eide H, Hafskjold L, Ruud I, Holmstrom IK Characteristics of communication with older people in home care: a qualitative analysis of audio recordings of home care visits. J Clin Nurs. 2017;26(23-24):4613-21.

28. Caris-Verhallen WM, Kerkstra A, van der Heijden PG, Bensing JM. Nurseelderly patient communication in home care and institutional care: an explorative study. Int J Nurs Stud. 1998;35(1-2):95-108

29. Lindström A, Heinemann T. Good enough: low-grade assessments in caregiving situations. Res Lang Soc Interact. 2009;42(4):309-28.

30. Wälivaara B-M, Sävenstedt S, Axelsson K. Caring relationships in home-based nursing care - registered nurses' experiences. Open Nurs J. 2013;7:89-95.

31. Wälivaara B-M, Sävenstedt $S$, Axelsson K. Encounters in home-based nursing care - registered nurses' experiences. Open Nurs J. 2013;7:73-81.

32. Grundberg A, Ebbeskog B, Gustafsson SA, Religa D. Mental healthpromoting dialogues from the perspective of community-dwelling seniors with multimorbidity. J Multidiscip Healthc. 2014:7:189-99.

33. Zimmermann C, Del Piccolo L, Bensing J, Bergvik S, De Haes H, Eide H, Fletcher I, Goss C, Heaven C, Humphris G, et al. Coding patient emotional cues and concerns in medical consultations: the Verona coding definitions of emotional sequences (VR-CoDES). Patient Educ Couns. 2011;82(2):141-8

34. Del Piccolo L, de Haes H, Heaven C, Jansen J, Verheul W, Bensing J, Bergvik S, Deveugele M, Eide H, Fletcher I, et al. Development of the Verona coding definitions of emotional sequences to code health providers' responses (VRCoDES-P) to patient cues and concerns. Patient Educ Couns. 2011:82(2):149-55.

35. Sundler AJ, Hoglander J, Eklund JH, Eide H, Holmstrom IK. Older persons' expressions of emotional cues and concerns during home care visits. Application of the Verona coding definitions of emotional sequences (VR-CoDES) in home care. Patient Educ Couns. 2017;100(2): $276-82$. 
36. Mjaaland TA, Finset A, Jensen BF, Gulbrandsen P. Patients' negative emotional cues and concerns in hospital consultations: a video-based observational study. Patient Educ Couns. 2011;85(3):356-62.

37. Heyn L, Finset A, Ruland CM. Talking about feelings and worries in cancer consultations: the effects of an interactive tailored symptom assessment on source, explicitness, and timing of emotional cues and concerns. Cancer Nurs. 2013;36(2):E20-30.

38. Eide $H$, Sibbern $T$, Egeland T, Finset A, Johannessen T, Miaskowski C, Rustoen T. Fibromyalgia patients' communication of cues and concerns: interaction analysis of pain clinic consultations. Clin J Pain. 2011;27(7):602-10.

39. Green J, Jester R, McKinley R, Pooler A. Nurse-patient consultations in primary care: do patients disclose their concerns? J Wound Care. 2013;22(10):534.

40. Heaven CM, Maguire P. Disclosure of concerns by hospice patients and their identification by nurses. Palliat Med. 1997;11(4):283-90.

41. Hafskjold L, Sundling V, van Dulmen S, Eide H. The use of supportive communication when responding to older people's emotional distress in home care - an observational study. BMC Nurs. 2017;16(1):24

42. Del Piccolo L, Mazzi MA, Goss C, Rimondini M, Zimmermann C. How emotions emerge and are dealt with in first diagnostic consultations in psychiatry. Patient Educ Couns. 2012;88(1):29-35.

43. Finset $A$, Heyn $L$, Ruland C. Patterns in clinicians' responses to patient emotion in cancer care. Patient Educ Couns. 2013;93(1):80-5.

44. Heyn L, Ruland CM, Finset A. Effects of an interactive tailored patient assessment tool on eliciting and responding to cancer patients' cues and concerns in clinical consultations with physicians and nurses. Patient Educ Couns. 2012;86(2):158-65.

45. Del Piccolo L, Pietrolongo E, Radice D, Tortorella C, Confalonieri P, Pugliatti M, Lugaresi A, Giordano A, Heesen C, Solari A, et al. Patient expression of emotions and neurologist responses in first multiple sclerosis consultations. PLoS One. 2015;10(6):e0127734.

46. Butalid L, Verhaak PF, Bensing JM. Changes in general practitioners' sensitivity to patients' distress in low back pain consultations. Patient Educ Couns. 2015;98(10):1207-13.

47. Mjaaland TA, Finset A, Jensen BF, Gulbrandsen P. Physicians' responses to patients' expressions of negative emotions in hospital consultations: a video-based observational study. Patient Educ Couns. 2011;84(3):332-7.

48. Uitterhoeve R, Bensing J, Dilven E, Donders R, deMulder P, van Achterberg T. Nurse-patient communication in cancer care: does responding to patient's cues predict patient satisfaction with communication. Psychooncology. 2009;18(10):1060-8.

49. Schirm V, Albanese T, Garland TN, Gipson G, Blackmon DJ. Caregiving in nursing homes. Views of licensed nurses and nursing assistants. Clin Nurs Res. 2000;9(3):280-97.

50. Clarke DM. Growing old and getting sick: maintaining a positive spirit at the end of life. Aust J Rural Health. 2007;15(3):148-54.

51. Bakeman R, Quera V. Sequential analysis and observational methods for the behavioral siences. New York: Camebridge University Press; 2011.

52. Eide H, Hafskjold L, Sundling V, van Dulmen S: Person-Centred communication research: Systematic Observation of Real Life Practice. In: Person-Centred healthcare research. Edited by McCormack B, van Dulmen S, Eide H, Skovdahl K, Eide T. UK: John Wiley \& Sons, Inc.; 2017: 191-200.

53. Eide $H$, Eide T, Rustoen T, Finset A. Patient validation of cues and concerns identified according to Verona coding definitions of emotional sequences (VR-CoDES): a video- and interview-based approach. Patient Educ Couns. 2011;82(2):156-62.

54. Del Piccolo L, De Haes H, Heaven C, Jansen J, Verheul W, Finset A. Coding of health provider talk related to cues and concerns - manual for VR-CoDES In: European Association for Communication in healthcare. Verona Network on Sequence Analysis in European Association for Communication in Healthcare; 2009. p. 1-17. http://www.each.eu/research/r-activities/sigs/ verona-coding-system/.

55. Del Piccolo L. VR-CoDES and patient-centeredness. The intersection points between a measure and a concept. Patient Educ Couns. 2017;100(11):2135-7.

56. Piccolo LD, Finset A, Mellblom AV, Figueiredo-Braga M, Korsvold L, Zhou Y, Zimmermann C, Humphris G. Verona coding definitions of emotional sequences (VR-CoDES): conceptual framework and future directions. Patient Educ Couns. 2017;100(12):2303-11.

57. World Medical Association. World Medical Association Declaration of Helsinki: ethical principles for medical research involving human subjects. In: Association WM Fortaleza, editor. 64th WMA General Assembly. Brazil: World Medical Association; 2013.
58. Gallagher A, Li S, Wainwright P, Jones IR, Lee D. Dignity in the care of older people - a review of the theoretical and empirical literature. BMC Nurs. 2008;7(1):11.

59. Hallberg IR. Death and dying from old people's point of view. A literature review. Aging Clin Exp Res. 2004;16(2):87-103.

60. Golden J, Conroy RM, Bruce I, Denihan A, Greene E, Kirby M, Lawlor BA. Loneliness, social support networks, mood and wellbeing in communitydwelling elderly. Int J Geriatr Psychiatry. 2009;24(7):694-700.

61. Boen H, Dalgard O, Bjertness E. The importance of social support in the associations between psychological distress and somatic health problems and socio-economic factors among older adults living at home: a cross sectional study. BMC Geriatr. 2012;12(1):27.

62. Sundstrom M, Edberg AK, Ramgard M, Blomqvist K. Encountering existential loneliness among older people: perspectives of health care professionals. Int J Qual Stud Health Well-being. 2018;13(1):1474673.

63. Laffon de Mazieres C, Morley JE, Levy C, Agenes F, Barbagallo M, Cesari M, De Souto Barreto P, Donini LM, Fitten J, Franco A, et al. Prevention of functional decline by reframing the role of nursing homes? J Am Med Dir Assoc. 2017;18(2):105-10.

64. Wysocki A, Butler M, Kane RL, Kane RA, Shippee T, Sainfort F. Long-term services and supports for older adults: a review of home and communitybased services versus institutional care. J Aging Soc Policy. 2015;27(3):255-79.

65. Bodie GD, Burleson BR, Jones SM. Explaining the relationships among supportive message quality, evaluations, and outcomes: a dual-process approach. Commun Monogr. 2012;79(1):1-22.

66. Baldacchino DR. Nursing competencies for spiritual care. J Clin Nurs. 2006; 15(7):885-96.

67. Tornoe K, Danbolt LJ, Kvigne K, Sorlie V. A mobile hospice nurse teaching team's experience: training care workers in spiritual and existential care for the dying - a qualitative study. BMC Palliat Care. 2015;14:43.

68. van Dulmen S. Listen: when words don't come easy. Patient Educ Couns. 2017;100(11):1975-8

69. Hermsen LAH, Hoogendijk EO, van der Wouden JC, Smalbrugge M, Leone SS, van der Horst HE, Dekker J. Self-perceived care needs in older adults with joint pain and comorbidity. Aging Clin Exp Res. 2018;30(5):449-55.

70. Wells N, Pasero C, McCaffery M. Chapter 17. Improving the Quality of Care Through Pain Assessment and Management. In: Hughes RG, editor. Patient Safety and Quality: An Evidence-Based Handbook for Nurses. Rockville, MD: Agency for Healthcare Research and Quality, US; 2008.

71. Thome B, Dykes AK, Hallberg IR. Home care with regard to definition, care recipients, content and outcome: systematic literature review. J Clin Nurs. 2003:12(6):860-72.

72. Eloranta S, Routasalo P, Arve S. Personal resources supporting living at home as described by older home care clients. Int J Nurs Pract. 2008;14(4): 308-14.

73. Sorbye LW, Hamran T, Henriksen N, Norberg A. Home care patients in four Nordic capitals - predictors of nursing home admission during one-year followup. J Multidiscip Healthc. 2010;3:11-8.

74. Algera M, Francke AL, Kerkstra A, van der Zee J. Home care needs of patients with long-term conditions: literature review. J Adv Nurs. 2004;46(4): 417-29.

75. Ottenvall Hammar I, Dahlin-Ivanoff S, Wilhelmson K, Eklund K. Selfdetermination among community-dwelling older persons: explanatory factors. Scand J Occup Ther. 2016;23(3):198-206.

76. Svanstrom R, Johansson Sundler A, Berglund M, Westin L. Suffering caused by care-elderly patients' experiences in community care. Int J Qual Stud Health Well-being. 2013:8:20603.

77. Tomaka J, Thompson S, Palacios R. The relation of social isolation, loneliness, and social support to disease outcomes among the elderly. J Aging Health. 2006;18(3):359-84.

78. Hawthorne G. Perceived social isolation in a community sample: its prevalence and correlates with aspects of peoples' lives. Soc Psychiatry Psychiatr Epidemiol. 2008;43(2):140-50.

79. Salmon P, Young B. A new paradigm for clinical communication: critical review of literature in cancer care. Med Educ. 2017;51(3):258-68.

80. Mastel-Smith B, Binder B, Hersch G, Davidson HA, Walsh T. Storytelling by community-dwelling older adults: perspectives of home care workers. Res Gerontol Nurs. 2011:4(2):117-26.

81. Eloranta S, Arve S, Isoaho H, Welch A, Viitanen M, Routasalo P. Perceptions of the psychological well-being and care of older home care clients: clients and their carers. J Clin Nurs. 2010;19(5-6):847-55. 
82. Bastemeijer CM, Voogt L, van Ewijk JP, Hazelzet JA. What do patient values and preferences mean? A taxonomy based on a systematic review of qualitative papers. Patient Educ Couns. 2017;100(5):871-81.

83. Street RL Jr, Makoul G, Arora NK, Epstein RM. How does communication heal? Pathways linking clinician-patient communication to health outcomes. Patient Educ Couns. 2009;74(3):295-301.

84. Street RL Jr. The many "disguises" of patient-centered communication: problems of conceptualization and measurement. Patient Educ Couns. 2017; 100(11):2131-4.

85. Burleson BR, Sarason IG, Sarason BR. Understanding the outcomes of supportive communication: a dual-process approach. J Soc Pers Relat. 2009: 26(1):21-38

86. Borg C, Fagerstrom C, Balducci C, Burholt V, Ferring D, Weber G, Wenger C, Holst G, Hallberg IR. Life satisfaction in 6 European countries: the relationship to health, self-esteem, and social and financial resources among people (aged 65-89) with reduced functional capacity. Geriatr Nurs. 2008; 29(1):48-57.

87. Salmon P, Young B. The inseparability of emotional and instrumental care in cancer: towards a more powerful science of clinical communication. Patient Educ Couns. 2017;100(11):2138-40.

88. Oliveira VC, Refshauge KM, Ferreira ML, Pinto RZ, Beckenkamp PR, Negrao RF, Ferreira PH. Communication that values patient autonomy is associated with satisfaction with care: a systematic review. J Physiother. 2012;58(4):215-29.

89. McCormack LA, Treiman K, Rupert D, Williams-Piehota P, Nadler E, Arora NK Lawrence W, Street RL Jr. Measuring patient-centered communication in cancer care: a literature review and the development of a systematic approach. Soc Sci Med. 2011;72(7):1085-95.

90. Williams K, Herman R, Bontempo D. Comparing audio and video data for rating communication. West J Nurs Res. 2013;35(8):1060-73.

91. Henry SG, Jerant A, losif AM, Feldman MD, Cipri C, Kravitz RL. Analysis of threats to research validity introduced by audio recording clinic visits: selection bias, Hawthorne effect, both, or neither? Patient Educ Couns. 2015; 98(7):849-56.

92. Plano Clark VL, Ivankova NV. Mixed methods research : a guide to the field, vol. 3. Los Angeles, Calif: Sage; 2016.

93. Landis JR, Koch GG. The measurement of observer agreement for categorical data. Biometrics. 1977;33(1):159-74

94. Eide H, Quera V, Graugaard P, Finset A. Physician-patient dialogue surrounding patients' expression of concern: applying sequence analysis to RIAS. Soc Sci Med. 2004;59(1):145-55.

95. Lawton MP, Brody EM. Assessment of older people: self-maintaining and instrumental activities of daily living. Gerontologist. 1969;9(3):179-86.

Ready to submit your research? Choose BMC and benefit from:

- fast, convenient online submission

- thorough peer review by experienced researchers in your field

- rapid publication on acceptance

- support for research data, including large and complex data types

- gold Open Access which fosters wider collaboration and increased citations

- maximum visibility for your research: over $100 \mathrm{M}$ website views per year

At BMC, research is always in progress.

Learn more biomedcentral.com/submissions 